\title{
Pelvic Fractures and Associated Injuries in Patients Admitted to and Treated at Emergency Department of Tibebe Ghion Specialized Hospital, Bahir Dar University, Ethiopia
}

\author{
Biruk Ferede' \\ Asteray Ayenew ${ }^{2}$ \\ Worku Belay' \\ 'Department of Orthopedics and \\ Traumatology, Bahir Dar University, \\ College of Medicine and Health Science, \\ Bahir Dar, Ethiopia; ${ }^{2}$ Department of \\ Midwifery, Bahir Dar University, College \\ of Medicine and Health Science, Bahir \\ Dar, Ethiopia
}

Background: Pelvic fractures are high-risk injuries that require careful evaluation due to significant patient morbidity and mortality associated with damage to major blood vessels, nerves, and organs. Thus, the aim of this study was to assess pelvic fractures and associated injuries among patients presented at the emergency department of Tibebe Ghion Specialized Hospital, Bahir Dar, Ethiopia.

Methods: This is a cross-sectional study with a retrospective facility-based data collection technique. All patients who were managed for pelvic fracture from September 2018 to February 2021 were included. The patient's chart number was collected from the orthopedics surgery morning register sheet and their case folders were retrieved from the medical record department. We used a structured and pretested checklist, and chart review for data collection. The collected data were cleaned, coded, and entered into Epi Info version 7 and exported to SPSS version 24 for analysis. Binary logistic regression analysis was used to identify factors associated with a pelvic fracture.

Results: We studied 64 cases of pelvic fracture during the study period. Pelvic was common among males with a ratio of 7:1 and young population (15-35 years). The most common associated injuries were lower extremity 23 (35.9\%), abdominal injuries $16(25.0 \%)$, and urethral injury in 13 (20.3\%). Moreover, most patients with pelvic fracture have Tile A fracture $56.3 \%$, Tile C in 20 $(31.3 \%)$, and Tile B in $8(12.5 \%)$ patients. The road traffic accident was the most common cause of pelvic fracture in $56.3 \%$, followed by fall down accident $(28.1 \%)$, and bullet injury $(12.5 \%)$.

Conclusion: The incidence of pelvic fracture was high in the study area. It reflects the need for strong and multi-sectoral collaboration to prevent pelvic fracture. Additionally, it needs a careful, systematic management approach for survival, healing, and to address the associated complexities and the polytrauma nature.

Keywords: pelvic fracture, orthopedic surgery, Bahir Dar, Ethiopia

\section{Background}

Pelvic bone fracture is the most severe and life-threatening orthopedic injury with an incidence of $3-8 \%$ of all fractures. ${ }^{1,2}$ The severity of pelvic bone fracture can range from simple and mostly harmless type $\mathrm{A}$ to life-threatening, complex type $\mathrm{C}$ fracture. The clinical presentation and outcomes of the pelvic fracture depend on the hemodynamic status of patients. Managing patients with a pelvic fracture is challenging both from the diagnostic and therapeutic perspective especially in resource-limited settings where medical facilities and infrastructure are scarce. ${ }^{3,4}$ 
Blunt traumatic injuries, with high energy disruptions like motor vehicle crashes (cars and motorcycles), pedestrian and bicycles hit by vehicles, and falls from height are the main mechanisms of pelvic injuries. But still, low energy trauma may lead to pelvic fracture in some patients, among the elderly.,

Pelvic fractures may also be presented with other associated injuries, particularly peripelvic soft tissue injuries, abdominal injuries, extremity fractures, chest, brain, and other body parts. ${ }^{7}$ The severity of fracture dictates the overall injury severity, which might result in catastrophic events including death. ${ }^{8,9}$ The rate of in-hospital mortality from pelvic fracture ranges from $5 \%$ to $20 \%$, but might go up to $50 \%$ in case of open compound fracture and resource-limited setting where medical equipment and resuscitation materials are not available. This high mortality is mainly attributed to the high hemodynamic instability from disruption of venous and arterial vessel near the fracture, the exposed ends of fracture, injuries to brain, chest, urogenital region, and multi organ failure. ${ }^{10-12}$ Moreover, sepsis, pelvic hematoma, actual renal failure, coagulopathy (60-65\%) and hemorrhagic shock are crucial causes for mortality in patients with pelvic fracture. ${ }^{13}$

Globally, an estimated 1.2 million people die from road crash accidents, and for each death from trauma, three victims were suffered from a permanent disability. ${ }^{14}$ Moreover, trauma is the third major cause of ischemic cardiovascular disease and occurrence of depression among victims and family members. ${ }^{15-18}$

Apart from death, pelvic bone fracture results in disability, nerve injury and paralysis, bladder injury and difficulty of urine passage, amputation, psychological trauma, and other complications. Pelvic fracture also exerts a heavy economic burden on individuals, families, and society resulting from health care costs, productivity loss, and occurrence of dependency from disability and seeking care from family members. ${ }^{19}$

Admission of patients with pelvic fracture, especially unstable patients, represent a complex life-threatening scenario that needs integrated medical hands and necessitates early aggressive resuscitation and prompt surgical intervention. ${ }^{20}$ Additionally, it is vital to deal with the pelvis as a visceral organ with multiple source of bleeding and organ failure. ${ }^{21}$

A better characterization of pelvic fracture is crucial to guide the decision making process for better management of patients for survival, healing, and improvement of patients, and for better clinical outcome in patients with pelvic fracture. ${ }^{21}$ This study aims to describe the incidence of pelvic fracture among patients presented at TGSH, Northwest Ethiopia to develop effective strategies in preventing pelvic fracture, to promote care given for patients including a multidisciplinary approach for resuscitation, survival, and better clinical outcomes.

\section{Methods}

\section{Study Area and Period}

We conducted a retrospective cross sectional study design from September 2018 to February 2021 in TGSH, Bahir Dar University, Bahir Dar Ethiopia. TGSH is a University hospital, and one of the 43 governmental hospitals in Amhara region. The hospital serves more than five million people in the catchment area. This teaching hospital has more than 500 beds, and 2000 patients per day in both inpatient and outpatient services. The Department of orthopedic surgery has both inpatient and outpatient services. There are 66 beds in the inpatient, a total of 14 orthopedic surgeons ( 2 of them are on fellowship), and 40 orthopedic specializing residents. Operations are done 4 days a week as elective cases and daily for emergency cases. The department has its own major operation room with three operating tables.

\section{Study Design}

A facility-based retrospective cross-sectional study design was used.

\section{Source Population}

The patient's admitted and treated at TGSH from September 2018 to February 2021.

\section{Study Population}

Patients who had a pelvic fracture from September 2018 to February 2021.

\section{Inclusion and Exclusion Criteria Inclusion Criteria}

Patients with pelvic fracture and managed at TGSH were included.

\section{Exclusion Criteria}

Patients referred from other health facilities to TGSH for complications like blood transfusion, intensive care unit admission, and patients with missed medical chart were excluded. Additionally, those who died within minutes after arrival of orthopedic emergency were excluded. 


\section{Data Collection}

The data were collected by three doctors of trained General Practitioners. The folder number of patients with pelvic fracture who present at TGSH from September 2018 to February 2021 were collected from the orthopedic morning section register sheets. Moreover, the medical charts were retrieved from the medical record department, and a structured checklist was used to collect the variables like socio-demographic variables (age, sex, the residence of the patient) and patient diagnosis, mechanism of injury, classification including investigations regarding the underlying pelvic fracture (imaging, documentation from orthopedic surgeon), condition on discharge, the number of days or months on treatment from chart review was extracted by the data collectors.

\section{Clinical Variables}

The data gathered from each patient included: age, sex, residency, residence of patient, etiology (mechanism of injury), and associated injuries. Additionally, pelvic radiography of each patient was identified, and the patterns (classification) of pelvic fracture were classified as Type A, B, C according to Tile classification of pelvic fracture ${ }^{22}$ (Table 1). The classification was based on the findings from surgeons and orthopedic surgeons, and confirmed by surgical and radiological records.

\section{Statistical Analysis}

The collected data were cleaned, coded and entered into the Epi Info version 7 and then exported to SPSS version 24. Descriptive statistics and chi-square were used, and graphical presentations such as tables, bar, and pie charts were used to present the result findings.

\section{Data Quality Control}

The checklist was pretested before the actual data collection, and modified based on the pretest result. Training was given to data collectors on how to collect the data and confidentiality of patient's information.

\section{Result}

\section{Socio-Demographic Characteristics of Study Participants}

A total of 64 patients were involved in this study. The majority of the cases $56(87.5 \%)$ were male, and $8(12.5 \%)$ were female with a ratio of 7:1. Regarding the age of patients, the mean age of patients was $31.93 \pm 12.1 \mathrm{SD}$ years, and the commonly affected age group was between 26-35 years (40.6\%) followed by $15-25$ years $(34.4 \%)$. Those patients who were between $36-45$ years and those above $46-55$ years were $4.7 \%$ and $17.2 \%$ respectively (Table 2).

\section{The Incidence of Pelvic Bone Fracture Among the Study Participants}

This was a facility-based retrospective cross-sectional study for the cases of pelvic fracture admitted and treated at the emergency of TGSH. We identified 3250 patients during the study period from September 2018 to February 2021, and there were 66 cases of pelvic fracture. Among the pelvic fracture cases, 2 charts were lost from the medical record department and not included in the study. This gives an incidence of pelvic fracture of $1.97 \%$.

\section{Associated Injuries}

Out of the sixty-four, $52(81.3 \%)$ patients had associated injuries of various types. The most common associated injury in this study was lower extremity, 23 (35.9\%), and abdominal injuries, 16 (25.0\%). Other involved as follows: chest, 11 (17.2\%); bladder, 2 (3.1\%); urethral injury, 13 (20.3\%); upper extremity, 12 (18.8\%); vertebral injury 6 (9.4\%); head injury, 12 (18.8\%); and nerve injury, 6 $(9.4 \%)$ (Table 3 and Figure 1$)$. The majority of patients with associated injuries were from Type A classification.

\section{Types of Pelvic Fracture and Managements}

Out of the sixty-four enrolled patients, most of them have Type A fracture comprising $56.3 \%$, Type $\mathrm{C}$ pelvic fracture, $20(31.3 \%)$, and Type B, 8 (12.5\%) (Figure 2 and Table 4). Thirty-four $(53.1 \%)$ patients with pelvic fracture managed with non-operative intervention while twenty (31.3\%) patients were referred to a higher center. Majority of patients (24/36) with Type A fracture managed non-operatively whereas, of patients with Type C, most (12/20) were referred to higher Addis Ababa.

\section{Pelvic Bone Fracture Outcomes and Length of Hospital Stay}

In this study, the length of hospital stay after having pelvic bone fracture ranges from 1-120 days with a mean of 12.08 days ( $\mathrm{SD} \pm 25.12$ days) and with a mean time presentation to emergency department of 17.98 hours (SD \pm 27.69 hours) and range of presentation to the 
Table I The Tile Classification of Pelvic Bone Fracture

\begin{tabular}{|c|c|}
\hline Type & Description \\
\hline \multirow[t]{3}{*}{ Type A: stable and posterior arch is intact } & $\begin{array}{l}\text { AI: fracture does not involve the pelvic ring(avulsion facture or fracture of the iliac } \\
\text { wing) } \\
\text { - AI.I.I: lliac spine } \\
\text { - AI.I.2: lliac crest } \\
\text { - AI.I.3: Ischial tuberosity }\end{array}$ \\
\hline & $\begin{array}{l}\text { A2: Stable or minimal displaced fracture of the pelvic ring } \\
\text { - A2.1: lliac wing fracture } \\
\text { - A2.2: lliac wing fracture unilateral fracture of anterior arch } \\
\text { - A2.I: bifocal fracture of anterior arch }\end{array}$ \\
\hline & $\begin{array}{l}\text { A3: transverse fracture of the sacrum } \\
\text { - A3.I: Sacrococcygeal dislocation } \\
\text { - A3.2: Sacrum undisciplined } \\
\text { - A3.3: Sacrum displaced }\end{array}$ \\
\hline \multirow[t]{3}{*}{$\begin{array}{l}\text { Type B: rotationally unstable, vertically stable-incomplete } \\
\text { disruption of the posterior arch }\end{array}$} & $\begin{array}{l}\text { BI: Open book injury (external rotation) } \\
\text { - BI.I: Sacroiliac joint, anterior disruption } \\
\text { - BI.2: Sacral fracture }\end{array}$ \\
\hline & $\begin{array}{l}\text { B2: Lateral compression injury(internal rotation) } \\
\text { - B2.I: Anterior compression fracture, sacrum } \\
\text { - B2.2: partial sacroiliac joint fracture, sacrum } \\
\text { - B2.3: Incomplete posterior iliac fracture }\end{array}$ \\
\hline & $\begin{array}{l}\text { B3: Bilateral type B fracture } \\
\text { - B3.I: Bilateral open book fracture } \\
\text { - B3.2: Open book fracture and lateral compression } \\
\text { - B3.3: Bilateral lateral compression }\end{array}$ \\
\hline \multirow[t]{3}{*}{$\begin{array}{l}\text { Type C: rotationally and vertically unstable - complete } \\
\text { disruption of the posterior arch }\end{array}$} & $\begin{array}{l}\text { CI: Unilateral fracture } \\
\text { - CI.I: fracture of the iliac bone } \\
\text { - CI.I: Sacroiliac dislocation and/or fracture dislocation } \\
\text { - CI.I: Sacral fracture }\end{array}$ \\
\hline & $\begin{array}{l}\text { C2: Bilateral fracture with one sided type B fracture (rotationally unstable) and one } \\
\text { sided type } C \text { fracture (vertically unstable) }\end{array}$ \\
\hline & $\begin{array}{l}\text { C2: Bilateral fracture with both sided type } C \text { fracture (both sides completely } \\
\text { unstable unstable) }\end{array}$ \\
\hline
\end{tabular}

Table 2 Sociodemographic Characteristics of Pelvic Bone Fracture in TGSH from September 2018 to February 202I $(n=64)$

\begin{tabular}{|l|l|l|l|}
\hline Variables & $\begin{array}{l}\text { Category } \\
\text { (Years) }\end{array}$ & Frequency & $\begin{array}{l}\text { Percentage } \\
\text { (100\%) }\end{array}$ \\
\hline Age & $15-25$ & 22 & 34.4 \\
& $26-35$ & 26 & 40.6 \\
& $36-45$ & 3 & 4.7 \\
& $46-55$ & 11 & 17.2 \\
& $56-65$ & 2 & 3.1 \\
\hline \multirow{2}{*}{ Age } & Male & 64 & 87.5 \\
& Female & 8 & 12.5 \\
\hline
\end{tabular}

emergency department was from 1-144 hours. From 64 cases, majority of 36 (56.3\%) were recovered, 22 (34.4) referred, $4(6.3 \%)$ went against medical advice and there were $2(3.1 \%)$ deaths (Table 5).

\section{Mechanism of Injury}

The RTA was the first cause of pelvic bone fracture, $56.3 \%$ of cases, followed by fall down accident (28.1\%), and bullet injury (12.5\%). From those involved in RTA, the most affected victims were passengers $(37.5 \%)$ followed by pedestrians $(15.6 \%)$. Among patients presenting with fall down accident, fall from height accounted for $62.5 \%$, 
Table 3 Associated Injury in Each Type of Fracture in Pelvic Ring Fracture in TGSH, Bahir Dar, Ethiopia

\begin{tabular}{|l|l|l|l|l|}
\hline \multirow{2}{*}{ Associated Injuries } & \multicolumn{3}{|l|}{ Type of Fracture } & \multirow{2}{*}{ Total } \\
\cline { 2 - 4 } & Tile A & Tile B & Tile C & \\
\hline Yes & 28 & 8 & 16 & 52 \\
\hline No & 8 & 0 & 4 & 12 \\
\hline Total & 36 & 8 & 20 & 64 \\
\hline
\end{tabular}

and object falls on patient accounted for $37.5 \%$. Regarding pattern of fracture, among those presented with RTA, 18 patients were with Type A fracture, 14 were with Type C fracture, and only $4 \%$ with Type B fracture (Figure 3 and Table 6).

\section{Discussion}

The frequency of pelvic fracture in this study was relatively high, which represents the severe nature of trauma in the young population. The result is line with the studies done in Germany, Sweden, and UK. ${ }^{23-25}$ The age distribution of pelvic fracture patients in TGSH was a mean of 31.93 years $(\mathrm{SD} \pm 12.1)$ and mode and median of 35 and 29 years respectively with male predominance $(87.5 \%)$. This result is supported by a study done in Saudi Arabia, $25.3 \pm 16.8$ years range and male $64.3 \%$, ${ }^{22}$ West Africa, mean age 34.3 years sex ratio $2: 1{ }^{26}$ but lower and reverse to the study done in Miami, 64.5 years \pm 25.6 years and $69.7 \%$ were female. ${ }^{27}$ The possible reason might be in Ethiopia, the majority of the population is young, and males predominantly run the economy of the household which in turn increases accidents and pelvic fracture among men and the young age group. However, in a study conducted in Addis Ababa the mean age of trauma patients were older, $(40.35 \pm 17.92$ years $) .{ }^{28}$ This can be explained as Addis Ababa is the capital city of Ethiopia, the availability of facilities like traffic light and police, and the nature of road decrease the occurrence of road traffic accidents. Moreover, in Addis Ababa the probability of having family and being responsible at young age might be lower.

In this study, the most common pelvic fracture was Type A comprising $56.3 \%$, followed by Type C pelvic fracture, $20(31.3 \%)$, and Type B, 8 (12.5\%). The result was in line with a study done in Korea (Type A $54.5 \%$, Type B $36.9 \%$, and Type C $8.6 \%)^{8}$

Thirty-four (53.1\%) patients with pelvic fracture managed with non-operative intervention while twenty $(31.3 \%)$ patients were referred to a higher center. Majority of patients 24/36 with Type A fracture managed non-operatively, whereas patients with Type C most (12/ 20) were referred to higher Addis Ababa.

This study revealed that $36 / 64$ (56.3\%) sustained pelvic fracture from road traffic accident and 18/64 (28\%) a fall down which is similar to the study done in UK $(62.9 \%$ and $30.6 \%$ respectively) ${ }^{23}$ and in Tanzania RTA accounts for $80 \%{ }^{29}$ so did in west Africa in which RTA accounts for $79 \%{ }^{26}$ and Taiwan $(62 \%){ }^{30}$ In this study among the cases of RTA, the majority of victims of pelvic fracture was passengers accounted for $66.7 \%$, followed by pedestrians $10(27.8 \%)$ and drivers $2(5.6 \%)$ which is similar with the study done at Addis Ababa, RTA accounts for 19 people (49\%) followed by pedestrian $15(38 \%)$ and drivers 5 $(13 \%) .{ }^{31}$ The possible reason might be passangers and

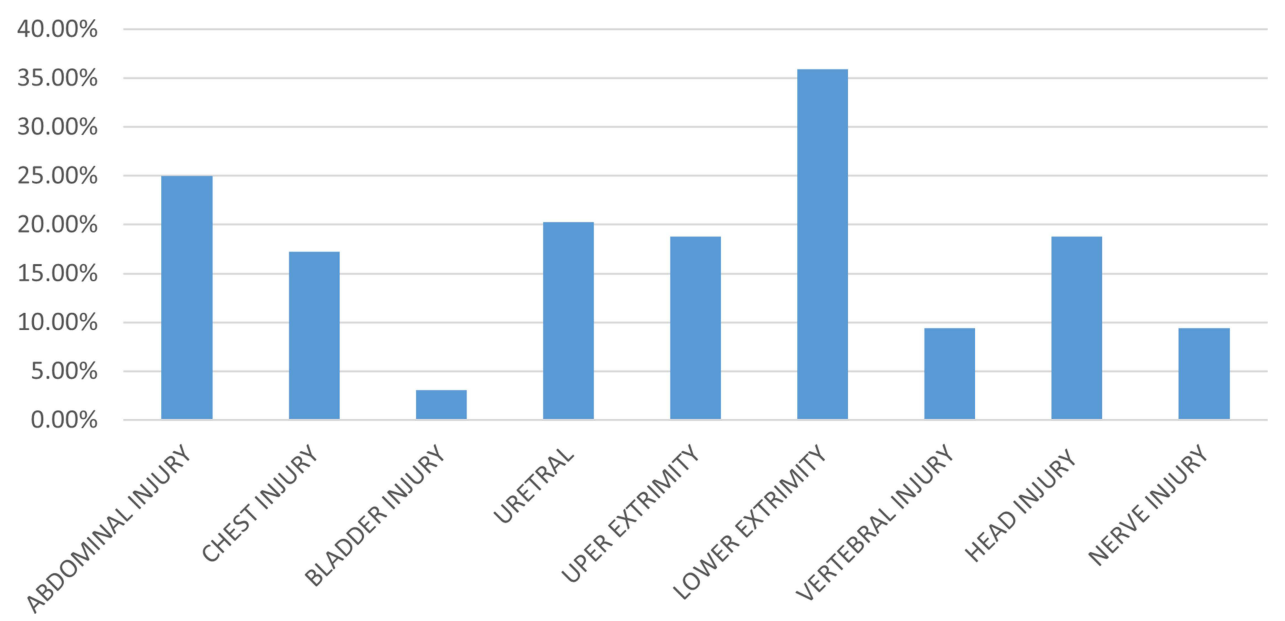

Figure I Associated injuries resulting from pelvic bone fracture in TGSH, Bahir Dar, Ethiopia. 


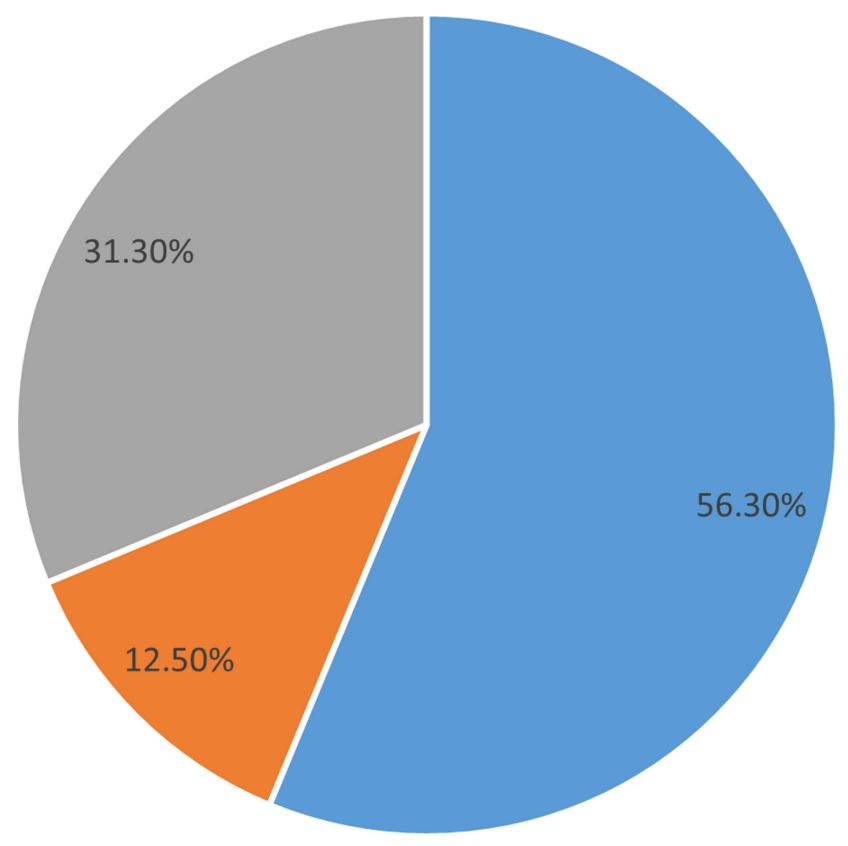

- Type A - Type B - Type C

Figure 2 Pattern of fractures in pelvic bone fracture in TGSH, Bahir Dar, Ethiopia.

pedestrians did not use seatbelt during traveling which in turn increase the occurrence of pelvic fracture and other associated fatal injuries.

The result of this study revealed that, $18.8 \%$ of patients had isolated pelvic fracture. The result is supported by a study done in Taiwan (25.8\%), ${ }^{30}$ and Addis Ababa, 75\% of pelvic fractures were isolated fracture. ${ }^{31}$ Moreover, the incidence of abdominal injury, 16 (25.0\%) was higher from all associated injuries which was supported by study done in Taiwan $(16.5 \%-30.7 \%),{ }^{30}$ and Addis Ababa 4/14 (28.6\%). ${ }^{31}$ The possible reason might be abdominal injuries are more likely in side-on collisions, high energy blunt trauma, road traffic accident, fall, and crush injuries and liver, spleen, and kidney most likely organs to be damaged.

Table 4 Intervention for Pelvic Bone Fracture in TGSH, Bahir Dar, Ethiopia

\begin{tabular}{|l|l|l|}
\hline Interventions & Frequency & Percent \\
\hline Non Operative & 34 & 53.1 \\
\hline Surgical & 10 & 15.6 \\
\hline Referred & 20 & 31.3 \\
\hline Total & 64 & 100.0 \\
\hline
\end{tabular}

Table 5 Outcome in Pelvic Bone Fracture in TGSH, Bahir Dar, Ethiopia

\begin{tabular}{|l|l|l|}
\hline Outcome & Frequency & Percent \\
\hline Recovered & 36 & 56.3 \\
Death & 2 & 3.1 \\
Referred & 22 & 34.4 \\
Went against medical advice & 4 & 6.3 \\
Total & 64 & 100.0 \\
\hline
\end{tabular}

Additionally, this study revealed that 36 (56.3\%) pelvic fractures were caused by RTA. The result was in line with study done in Taiwan $(62 \%),{ }^{30}$ German $(34 \%),{ }^{32}$ and Addis Ababa (65\%). ${ }^{31}$ This can be explained as road traffic accident is a common public health problem in Ethiopia, and the World Health Organization categorized Ethiopia as one of the worst countries in the world. ${ }^{33}$

\section{Limitation}

As this study was retrospective in its design, 2 medical charts were not available (missed) and excluded from the study.

\section{Conclusion}

The incidence of pelvic fracture in this study was relatively high. According to this study the most commonly affected

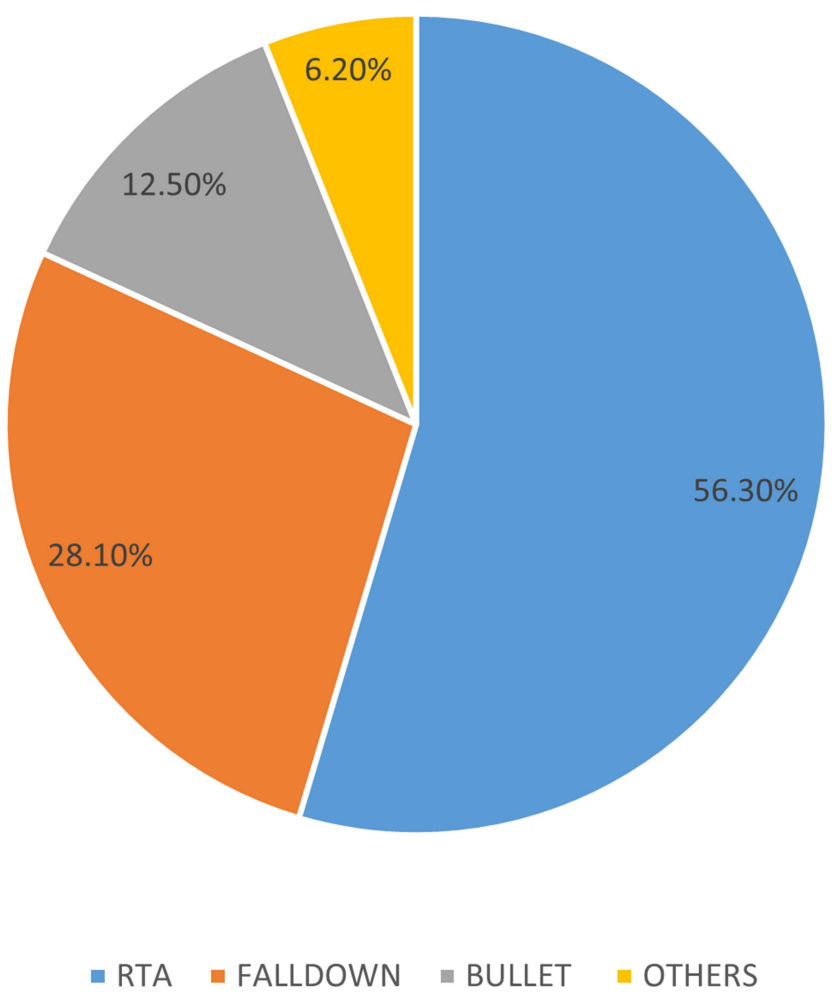

Figure 3 Mechanism of injuries for pelvic bone fracture in TGSH, Bahir Dar, Ethiopia. 
Table 6 Mechanisms in Each Type of Fracture in Pelvic Ring Fracture in TGSH, Bahir Dar, Ethiopia

\begin{tabular}{|l|l|l|l|l|l|}
\hline \multirow{2}{*}{$\begin{array}{l}\text { Type of } \\
\text { Fracture }\end{array}$} & \multicolumn{4}{|l|}{ Mechanism } & \multirow{2}{*}{ Total } \\
\cline { 2 - 5 } & $\begin{array}{l}\text { Road Traffic } \\
\text { Accident }\end{array}$ & $\begin{array}{l}\text { Fall } \\
\text { Down }\end{array}$ & Others & Bullet & \\
\hline Type A & 18 & 8 & 2 & 8 & 36 \\
Type B & 4 & 4 & 0 & 0 & 8 \\
Type C & 14 & 6 & 0 & 0 & 20 \\
\hline Total & 36 & 18 & 2 & 8 & 64 \\
\hline
\end{tabular}

with pelvic ring fracture was male with M:F ratio of 7:1. Commonly affected population was young age group (15-35 years), and the most common cause of pelvic fracture was road traffic accident, thus pedestrians and passengers were victims. Fall down from a height also accounts for a significant number. The majority of pelvic fracture patients in this study were diagnosed as type A fracture. Abdominal, lower extremity and ureteral injuries were the major associated injuries for patients with pelvic injuries. To reduce pelvic fracture and its complication, interventional programs to reduce car accident, and effective treatment, characterization of pelvic fracture is crucial to guide the decision making process for better management of patients for survival, healing, improvement of patients, and for better clinical outcome in patients with pelvic fracture.

\section{Abbreviations}

RTA, Road Traffic Accident; TGSH, Tibebe Ghion Specialized Hospital.

\section{Data Sharing Statement}

All necessary information are available from the corresponding author on reasonable request through mambusta2@gmail.com.

\section{Ethical Consideration}

This study was conducted in accordance with the Declaration of Helsinki. Ethical clearance was obtained from Bahir Dar University College of Medicine and Health Science Ethical Review Board (IRB) office. The letter of support was written by the Orthopedic and Trauma department to Tibebe Ghion Specialized Hospital managing director and card office for supporting data collectors by providing medical chart and other necessary information. Additionally, informed consent was waived by Ethical Review Board (IRB) office of the college, and information from patient medical chart and orthopedic morning registering sheet was used only for the purpose of this research and confidentiality was kept during the study and dissemination of the results.

\section{Acknowledgment}

We would like to acknowledge Bahir Dar University College of Medicine and Health Science for funding and approval of ethical clearance to carry out this research. We also would like to thank Tibebe Ghion Specialized Hospital managing director and card office for their unreserved support, and data collectors for their hard work.

\section{Author Contributions}

All authors made a significant contribution to the work reported, whether that is in the conception, study design, execution, acquisition of data, analysis and interpretation, or in all these areas; took part in drafting, revising or critically reviewing the article; gave final approval of the version to be published; have agreed on the journal to which the article has been submitted; and agree to be accountable for all aspects of the work.

\section{Funding}

The source of funding for this research was Bahir Dar University College of Medicine and Health Science, and the funding organization has no role in design, data collection, analysis and interpretation.

\section{Disclosure}

All authors declared that they have no competing interest.

\section{References}

1. Arvieux C, Thony F, Broux C, et al. Current management of severe pelvic and perineal trauma. J Visc Surg. 2012;149(4):e227-38. doi:10.1016/j.jviscsurg.2012.06.004

2. Cullinane DC, Schiller HJ, Zielinski MD, et al. Eastern Association for the Surgery of Trauma practice management guidelines for hemorrhage in pelvic fracture-update and systematic review. $J$ Trauma. 2011;71(6):1850-1868. doi:10.1097/TA.0b013e31823dca9a

3. Magnone S, Coccolini F, Manfredi R, et al. Management of hemodynamically unstable pelvic trauma: results of the first Italian consensus conference (cooperative guidelines of the Italian Society of Surgery, the Italian Association of Hospital Surgeons, the Multi-specialist Italian Society of Young Surgeons, the Italian Society of Emergency Surgery and Trauma, the Italian Society of Anesthesia, Analgesia, Resuscitation and Intensive Care, the Italian Society of Orthopaedics and Traumatology, the Italian Society of Emergency Medicine, the Italian Society of Medical Radiology -Section of Vascular and Interventional Radiology- and the World Society of Emergency Surgery). World J Emerg Surg. 2014;9(1):18. doi:10.1186/17497922-9-18 
4. Grotz MR, Allami MK, Harwood P, Pape HC, Krettek C, Giannoudis PV. Open pelvic fractures: epidemiology, current concepts of management and outcome. Injury. 2005;36(1):1-13. doi:10.1016/j. injury.2004.05.029

5. Abdelrahman H, El-Menyar A, Keil H, et al. Patterns, management, and outcomes of traumatic pelvic fracture: insights from a multicenter study. J Orthop Surg Res. 2020;15(1):249. doi:10.1186/ s13018-020-01772-w

6. Rommens PM, Wagner D, Hofmann A. Minimal invasive surgical treatment of fragility fractures of the pelvis. Chirurgia (Bucur). 2017;112(5):524-537. doi:10.21614/chirurgia.112.5.524

7. Demetriades D, Karaiskakis M, Velmahos GC, Alo K, Murray J, Chan L. Pelvic fractures in pediatric and adult trauma patients: are they different injuries? J Trauma. 2003;54(6):1146-51; discussion 51. doi:10.1097/01.TA.0000044352.00377.8F

8. Kim MJ, Lee JG, Lee SH. Factors predicting the need for hemorrhage control intervention in patients with blunt pelvic trauma: a retrospective study. BMC Surg. 2018;18(1):101. doi:10.1186/s12893018-0438-8

9. Thiyam R, Lalchandani R, Satyaprakash S, Godara N. Uncontrolled haemorrhage in pelvic fracturesd - can the inevitable be avoided? Chin J Traumatol. 2016;19(1):54-55. doi:10.1016/j. cjtee.2015.08.007

10. Balogh Z, King KL, Mackay P, et al. The epidemiology of pelvic ring fractures: a population-based study. J Trauma Acute Care Surg. 2007;63(5):1066-1073. doi:10.1097/TA.0b013e3181589fa4

11. Bramos A, Velmahos GC, Butt UM, Fikry K, Smith RM, Chang Y. Predictors of bleeding from stable pelvic fractures. Arch Surg. 2011;146(4):407-411. doi:10.1001/archsurg.2010.277

12. Dechert TA, Duane TM, Frykberg BP, Aboutanos MB, Malhotra AK, Ivatury RR. Elderly patients with pelvic fracture: interventions and outcomes. Am Surg. 2009;75(4):291-295. doi:10.1177/ 000313480907500405

13. Patterson FP, Morton KS. The cause of death in fractures of the pelvis: with a note on treatment by ligation of the hypogastric (Internal Iliac) Artery. J Trauma Acute Care Surg. 1973;13(10).

14. Peden M. World report on road traffic injury prevention; 2004.

15. WHO Commission on Macroeconomics and Health \& World Health Organization. (2001). Macroeconomics and health : investing in health for economic development : executive summary / report of the Commission on Macroeconomics and Health. World Health Organization. Available form: https://apps.who.int/iris/handle/10665/ 42463.

16. World Health Organization. A 5 -year WHO strategy for road traffic injury prevention. Geneva; 2001.

17. Chandran A, Hyder AA, Peek-Asa C. The global burden of unintentional injuries and an agenda for progress. Epidemiol Rev. 2010;32 (1):110-120. doi:10.1093/epirev/mxq009

18. Murray CJ, Lopez AD. Mortality by cause for eight regions of the world: global burden of disease study. Lancet. 1997;349(9061):12691276. doi:10.1016/S0140-6736(96)07493-4

19. Kahlon IA, Hanif A, Awais SM. Analysis of emergency care of trauma patients with references to the type of injuries, treatment and cost. Ann King Edward Med Univ. 1970;16(1):28.
20. Gordon WT, Fleming ME, Johnson AE, Gurney J, Shackelford S, Stockinger ZT. Pelvic fracture care. Mil Med. 2018;183 (suppl_2):115-117. doi:10.1093/milmed/usy111

21. Papakostidis C, Giannoudis PV. Pelvic ring injuries with haemodynamic instability: efficacy of pelvic packing, a systematic review. Injury. 2009;40(Suppl 4):S53-61. doi:10.1016/j. injury.2009.10.037

22. Tile M. Acute pelvic fractures: i. causation and classification. $J \mathrm{Am}$ Acad Orthop Surg. 1996;4(3):143-151. doi:10.5435/00124635199605000-00004

23. Giannoudis PV, Grotz MR, Tzioupis C, et al. Prevalence of pelvic fractures, associated injuries, and mortality: the United Kingdom perspective. J Trauma Acute Care Surg. 2007;63(4):875-883. doi:10.1097/01.ta.0000242259.67486.15

24. Ragnarsson B, Jacobsson B. Epidemiology of pelvic fractures in a Swedish county. Acta Orthop Scand. 1992;63(3):297-300. doi: $10.3109 / 17453679209154786$

25. Pohlemann $\mathrm{T}$, Tscherne $\mathrm{H}$, Baumgärtel $\mathrm{F}$, et al. Pelvic fractures: epidemiology, therapy and long-term outcome. Overview of the multicenter study of the Pelvis Study Group. Der Unfallchirurg. 1996;99 (3):160-167.

26. Diouf AB, Gueye AB, Dembele B, et al. Trauma of the Pelvic Ring: epidemiological and etiopathogenic aspects. Biomed J Sci Tech Res. 2018;4(2):3787-3790.

27. Buller LT, Best MJ, Quinnan SM. A Nationwide Analysis of Pelvic Ring fractures: incidence and trends in treatment, length of stay, and mortality. Geriatr Orthop Surg Rehabil. 2016;7(1):9-17. doi:10.1177/ 2151458515616250

28. Hunchak C, Teklu S, Meshkat N, Meaney C, Puchalski Ritchie L. Patterns and predictors of early mortality among emergency department patients in Addis Ababa, Ethiopia. BMC Res Notes. 2015;8:605. doi:10.1186/s13104-015-1592-z

29. Lupondo, V., Museru, L., \& Mcharo, C. (2011). Forequarter Amputation at Muhimbili Orthopaedic Institute: indications and Outcome. East and Central African Journal of Surgery, 16.

30. Yang NP, Chan CL, Chu D, et al. Epidemiology of hospitalized traumatic pelvic fractures and their combined injuries in Taiwan: 2000-2011 National Health Insurance data surveillance. Biomed Res Int. 2014;2014:878601. doi:10.1155/2014/878601

31. Worku K. Analysis of the cause, classification and associated injuries of pelvic fracture in patients presenting to Tikur Anbessa specialized hospital emergency department, Addis Ababa, Ethiopia. Addis Ababa Universty; 2018.

32. Richter M, Otte D, Gänsslen A, Bartram H, Pohlemann T. Injuries of the pelvic ring in road traffic accidents: a medical and technical analysis. Injury. 2001;32(2):123-128. doi:10.1016/S0020-1383(00) 00171-6

33. Woyessa AH, Heyi WD, Ture NH, Moti BK. Patterns of road traffic accident, nature of related injuries, and post-crash outcome determinants in western Ethiopia - a hospital based study. Afr J Emerg Med. 2021;11(1):123-131. doi:10.1016/j.afjem.2020.09.008
Orthopedic Research and Reviews

\section{Publish your work in this journal}

Orthopedic Research and Reviews is an international, peer-reviewed, open access journal that focusing on the patho-physiology of the musculoskeletal system, trauma, surgery and other corrective interventions to restore mobility and function. Advances in new technologies, materials, techniques and pharmacological agents are particularly welcome. The manuscript management system is completely online and includes a very quick and fair peer-review system, which is all easy to use. Visit http://www.dovepress.com/testimonials.php to read real quotes from published authors. 